\title{
Antibacterial evaluation of Acacia nilotica Lam (Mimosaceae) seed extract in dermatological preparations
}

\author{
Olusola AREMU $1,3 *$ (D) , Olubunmi OLAYEMI 1 (D), Tolulope AJALA 4 (D), Yetunde ISIMI 1 (D), \\ Peters OLADOSU 5 (D), Kokonne EKERE 1 (D) , Judith JOHN 1 (D), Martins EMEJE 2 (D)
}

1 Department of Pharmaceutical Technology and Raw Materials Development, National Institute for Pharmaceutical Research and Development, Abuja, Nigeria.

2 Centre for Nanomedicine and Biophysical Drug Delivery, National Institute for Pharmaceutical Research and Development, Abuja, Nigeria.

3 Department of Pharmaceutics and Industrial Pharmacy, Faculty of Pharmaceutical Sciences, University of Ilorin, Ilorin, Nigeria.

4 Department of Pharmaceutics and Industrial Pharmacy, Faculty of Pharmacy, University of Ibadan, Ibadan, Nigeria.

5 Department of Microbiology and Biotechnology, National Institute for Pharmaceutical Research and Development, Abuja, Nigeria.

* Corresponding Author. E-mail: solabank@yahoo.com (O.A.); Tel. +234-803-325 9890.

Received: 05 April 2019 / Revised: 07 August 2019 / Accepted: 16 August 2019

\begin{abstract}
The plant Acacia nilotica Lam (Mimosaceae) has received a lot of recognition because of its ethno-medicinal claims, some of which have been justified by scientific studies. Various forms of its presentation like the liquor concentrates (decoction) and powders are used traditionally, however, none of these have been standardized to assure efficacy, safety, stability and appropriate dose delivery. The intention of this present work was to develop an antibacterial dermatological dosage formulation that will serve as a remedy for the treatment of skin diseases. The powdered seeds were macerated in methanol for $48 \mathrm{~h}$ and the resultant extract was formulated using Aqueous cream $\mathrm{BP}$ in which parabens was substituted for chlorocresol as preservative, while lipophilic ointment base, shea butter, was used at concentrations of 5.0, 7.5 and $10.0 \% \mathrm{w} / \mathrm{w}$ respectively. The formulations were evaluated physico-chemically and subsequently tested against selected organisms such as Staphylococcus aureus, Pseudomonas aeruginosa, Escherichia coli, Klebsiella pneumonia, Streptococcus pyrogens and Salmonella typhi which are commonly implicated in skin infections. Ciprofloxacin and commercially available Neomycin cream were used as reference compounds. The results showed that, all the preparations especially the ointment containing shea butter gave favourable physico-chemical characteristics and at $10.0 \% \mathrm{w} / \mathrm{w}$ concentration, exhibited significant antibacterial activity $(\mathrm{p}<0.05)$ against the microorganisms tested with activity against Staphylococcus aureus being the highest followed by Pseudomonas aeruginosa $>$ Streptococcus pneumonia $>$ Klebsiella pneumonia = Escherichia coli= Salmonella typhi. Therefore showing potential for development as a standardized dosage form for the treatment of skin infections where the interrogated organisms are implicated.
\end{abstract}

KEYWORDS: Acacia nilotica; shea butter; aqueous cream; antibacterial; skin.

\section{INTRODUCTION}

Medicinal plants and products obtained therefrom have served as sources of relief for ailments, promoting healing and maintaining good health for as long as time and existence itself. Plant compounds like other natural products are increasingly being used as non-toxic and potent substitutes for synthetically manufactured products [1].

In recent times, the increase in multi-drug resistant microbial strains and the advent of strains with decreasing susceptibility to antibiotics have attracted the attention of the World Health Organization (WHO), Scientists and Clinicians [2]. Studies have established that, bacterial resistance and antibiotic therapy failure can be related to the overuse or misuse of these drugs; the prominent being self-medication attributed to the cost of medical consultations, inadequate diagnosis, treatment and the ability of patients to purchase antibiotics without appropriate prescriptions [3, 4, 5, 6, 7, 8]. Administration of an antibiotic without prescription or on recommendation following diagnosis is most frequently accompanied by inadequate or

How to cite this article: Aremu O, Olayemi O, Ajala T, Isimi Y, Oladosu P, Ekere K, John J, Emeje M. Antibacterial evaluation of Acacia nilotica Lam (Mimosaceae) seed extract in dermatological preparations of the manuscript. J Res Pharm. 2020; 24(1): $170-181$. 
sub-therapeutic dosing and duration of treatment which can modulate the bacterial virulence. In addition, bacteria also possess the inherent ability to develop resistance to therapy. A number of effective and relatively inexpensive synthetic antibacterial drugs such as neomycin and ciprofloxacin hydrochloride have been used over the years in the region. The continued use of these drugs as seen in most of the developing countries where there is chaotic drug distribution, compounded by self-medication and drug abuse as well as irrational drug prescription, increases infection-related morbidity and mortality as a result of the drugs becoming ineffective $[3,4,5,6,7,8]$. Therefore, there is the need to continue to source new drugs with fewer propensities for resistance. The use of indigenous herbal medicines is an important strategy towards the attainment of this objective. This is because it would reduce cases of non-completion of therapy for economic reasons. In addition, resistance to multicomponent preparations, as is seen in herbal medicines, develops less rapidly [9]. Although more than 80 percent of the people in both the underdeveloped and the developed countries depend on herbal medicines for their medical needs, the major problem with herbal medicines in such countries still remains their poor and sometimes unhealthy presentation. Standardization of herbal medicines therefore, should be a major interest for researchers especially in Africa. A major aspect of this standardization process is the development of suitable dosage forms for these herbal medicines [9].

The plant, Acacia nilotica is an evergreen, single stemmed plant of the family; mimosaceae. It is indigenous to Northern Nigeria, West Africa, North Africa, and the subcontinents of India where it grows widely in the dry lands [10]. It is also known as Gum Arabic tree, Babul, Egyptian thorn, or Prickly acacia and in Nigeria, it is known as Bagaruwa among the Hausa speaking community. It is a plant of great importance in traditional, agricultural and pastoral systems [11]. Most parts of Acacia nilotica plant have found useful application in traditional/folklore medicine as such it is referred to as a versatile plant. Several bioactive secondary constituents like gallic acid, isoquercitin, terpenes, phenolic glycosides, volatile essential oils, ascorbic acid, carotene, calcium, magnesium and selenium contained in the plant have been indicated in its numerous biological activities $[1,13,12,14]$. Traditionally the leaves, flowers, fruit pods and bark have found use in various diseases like cancer, diarrhea, dysentery, hemorrhoids, tuberculosis, leprosy, fever, bronchial infections, wounds, ulcers, diabetes and also as astringent $[1,15,16,17,18,19]$. In some parts of West Africa, the stem bark and gum are used to treat tumors of the eye, ear, liver and spleen in some parts of West Africa while the root and woody stem are indicated in the treatment of tuberculosis and smallpox respectively [20,21]. In other regions of the world, the fresh root extracts are taken as narcotics while the stem gum dispersion is taken as an aphrodiasic; the branches of the tree is also chewed for cleansing the mouth and cleaning the teeth [22].

Several works have investigated these folklore beliefs of Acacia nilotica (AN) plant and suggested diverse applications, for example, El-Tahir et al [23] investigated the ethyl acetate extract of the Acacia nilotica fruit pods and reported that it was highly active against Plasmodium falciparum. Similarly, Alli et al [24 reported strong activity of the root extract of Acacia nilotica against Plasmodium falciparium, but, methanol root extract was described as been substantially active against chloroquine sensitive strains of Plasmodium berghei by Jigam et al [25]. In a similar but separate report, the activity of the methanol extract of the fruit pod was found to be significant in reducing blood pressure in vivo [19]. Sanni et al [26] studied and reported the antidiarrhoeal property of the ethyl acetate extract of the pod. We have previously reported from our laboratory, the timekill kinetics of the fruit pod extract Acacia nilotica; we showed that, the rate of kill was both time and concentration dependent for some of the organisms (Pseudomonas aeruginosa, Escherichia coli and Staphylococcus aureus) implicated in wound infections [27]; the present study is an advancement over that study. Other scientists who reported antimicrobial properties of the extracts of Acacia nilotica include, Abeer and Sanaa [28], who used clinical isolates of gram-negative and gram-positive bacteria obtained from wound abscesses of patients at Khartoum Hospital to interrogate the ethanol and chloroform extracts of the fruit, Kossi et al [29] who investigated the effect of the hydro-ethanol fruit pod extract in healing wounds due to burns and reported accelerated healing, Manga et al [30] who reported high antimicrobial activity of the aqueous and chloroform leaf extracts of this plant against known resistant Staphylococcus aureus and Pseudomonas aeruginosa.

Pharmaceutical semisolid formulations include ointments, gels, creams, emulsions and foams which convey drugs or active moieties intended for topical applications to membranes like the skin, buccal tissue, nasal mucosa, retina tissue, ear linings and vagina mucosa [31]. Ointments are formulations that consists of a base as the drug carrier and this influences the performance of such formulations. They have lubricating properties and are preferred as obstructing coverings over the affected skin where they prevent moisture loss and increase the duration of drug release and activity at the applied site [32]. Creams on the other hand are formulations which contain one or more active ingredient dissolved or dispersed in an oil in water $(\mathrm{o} / \mathrm{w})$ or 
water in oil (w/o) emulsion. They are cosmetically and aesthetically acceptable due to their soft texture, ease of application and spread on the required site and also ease of removal from the site of application [33]. Literature survey reveal no report on the formulation and standardization of extracts of Acacia nilotica despite the large scientific data justifying its folkloric use and efficacy. Consequently, this study was designed to develop dermatological formulations from the methanol extract of Acacia nilotica seeds, evaluate its physicochemical properties and assess the antibacterial activity against some organisms commonly implicated in wounds and skin infections.

\section{RESULTS AND DISCUSSION}

The yield of Acacia nilotica seed extract (ANSE) was calculated as $7.25 \% \mathrm{w} / \mathrm{w}$. This yield may require improvement via alternative means of extraction such as using highly polar organic solvents that will be able to dissolve more secondary metabolites or continuous extraction technique such as the use of Soxhlet apparatus, in order to support scale-up formulation of this extract since the plant is abundantly available in the wild, particularly in the tropics. The composition of the seed extract creams and ointments is shown in Table 1 while the organoleptic and physical properties of the formulated creams and ointments containing ANSE (Acacia nilotica seed extract) are shown in Table 2.

Table 1. Composition for the preparation of Acacia nilotica seed extract (ANSE) creams and ointments.

\begin{tabular}{ccccccccc}
\hline F0 & FP & F1 & F2 & F3 & S0 & S1 & S2 & S3 \\
\hline 7.5 & 7.5 & 7.5 & 7.5 & 7.5 & - & - & - & - \\
- & - & 1.250 & 1.875 & 2.500 & - & 1.250 & 1.875 & 2.500 \\
- & 0.025 & 0.025 & 0.025 & 0.025 & - & - & - & - \\
- & 0.0125 & 0.0125 & 0.0125 & 0.0125 & - & - & - & - \\
- & - & 2 & 2 & 2 & - & - & - & - \\
17.50 & 17.50 & 16.20 & 15.59 & 14.97 & - & - & - & - \\
- & - & - & - & - & 25 & 23.75 & 23.13 & 22.50 \\
\hline
\end{tabular}

$\mathrm{F} 0=$ formulation containing aqueous cream alone without preservative.

$\mathrm{FP}=$ formulation containing aquepus cream with preservative.

$\mathrm{F} 1, \mathrm{~F} 2$ and F3 = formulations containig ANSE at concentrations of 5.0, 7.5 and $10 \% \mathrm{w} / \mathrm{w}$ respectively.

$\mathrm{S} 0$ = formulation containing She butter alone.

S1, S2 and S3 = formulations containing ANSE at concentrations of 5.0, 7.5 and $10 \% \mathrm{w} / \mathrm{w}$ respectively.

Table 2. Physical properties of Acacia nilotica seed extract (ANSE) creams and ointments.

\begin{tabular}{|c|c|c|c|c|c|c|c|c|c|}
\hline Color & White & White & Brown & Dark & Dark & Light & Light & Dark & Dark \\
\hline & & & & brown & brown & yellow & brown & brown & brown \\
\hline Appearance & Smooth & Smooth & $\begin{array}{c}\text { Slightly } \\
\text { rough }\end{array}$ & $\begin{array}{c}\text { Slightly } \\
\text { rough }\end{array}$ & $\begin{array}{l}\text { Slightly } \\
\text { rough }\end{array}$ & Smooth & Smooth & Smooth & Smooth \\
\hline Odor & Odorless & Odorless & $\begin{array}{c}\text { Characteris } \\
\text { tic }\end{array}$ & Agreeable & Agreeable & Odorless & Earthy & Earthy & Earthy \\
\hline Texture & Smooth & Smooth & Smooth & Smooth & Smooth & Smooth & Gritty & Gritty & Gritty \\
\hline $\begin{array}{l}\text { Ease of } \\
\text { application }\end{array}$ & +++ & +++ & +++ & ++ & ++ & + & + & + & + \\
\hline Washability & +++ & +++ & +++ & ++ & ++ & + & + & + & + \\
\hline Irritancy & $\begin{array}{l}\text { Non- } \\
\text { irritant }\end{array}$ & $\begin{array}{l}\text { Non- } \\
\text { irritant }\end{array}$ & $\begin{array}{l}\text { Non- } \\
\text { irritant }\end{array}$ & $\begin{array}{l}\text { Non- } \\
\text { irritant }\end{array}$ & $\begin{array}{l}\text { Non- } \\
\text { irritant }\end{array}$ & $\begin{array}{l}\text { Non- } \\
\text { irritant }\end{array}$ & $\begin{array}{l}\text { Non- } \\
\text { irritant }\end{array}$ & $\begin{array}{l}\text { Non- } \\
\text { irritant }\end{array}$ & $\begin{array}{l}\text { Non- } \\
\text { irritant }\end{array}$ \\
\hline
\end{tabular}

$+=$ difficult to wash off, difficult to apply.

$++=$ moderately easy to wash off, moderately easy to apply.

+++ easy to wash off, easy to apply. 
Organoleptic evaluation of the dried extract revealed a brown shiny powder with an earthy odor. Phytochemical studies of A. nilotica seed extract had showed that tannins, flavonoids, glycosides and carbohydrates are present [34]. The presence of phytoconstituents in plants create appealing opportunities for the development of modern chemotherapies against wide range of microorganisms [35, 36].

The physical characteristics of the formulated ANSE creams such as the appearance, color, odor, feel on skin, texture, ease of application and removal are displayed in Table 2. The colour of the preparations with the different bases appeared from light brown to chocolate brown, increase in color intensity was observed as the concentration of the extract increased in the formulations. Generally, the colour of all the preparations was appealing hence colorants may not be necessary when scale-up production of these formulations is required.

The creams had a smooth appearance and were uniformly mixed except for the formulation with the highest concentration of extract $(10 \% \mathrm{w} / \mathrm{w})$ which had a gritty appearance, while the shea butter base (ointment) had smooth appearance irrespective of extract concentration. All the cream formulations were easily applied to the skin and easily removed under a running tap unlike the ointments that were greasy and could not be removed with water because of their hydrophobic nature. Both the cream and ointment preparations were non-irritating to the skin, with a soft and smooth feel. Fragrance may be introduced into the composition of the preparations to improve the odour during large scale production for aesthetic purposes and to encourage patient compliance. Extract-vehicle compatibility was observed for 90 days.

In about 30 days of storage, all the cream formulations except the formulation containing $10 \% \mathrm{w} / \mathrm{w}$ of the extract showed growth of mould. This may be as a result of failure of the parabens as preservative. The use of chlorocresol as a preservative may have been more effective as it is known to have greater preserving ability than parabens [37]. Also the water content in the composition (Table 1) is a strong factor that may support microbial contamination, as the concentration of the extract increases, the water content was decreasing which may explain why $10 \% \mathrm{w} / \mathrm{w}$ cream formulation with least water concentration did not support mould growth unlike those with higher concentrations of water. However, all ointment formulations remained physically stable throughout the duration of storage. Lipophilic base medicaments have been identified as being hostile for microbial contamination.

The creams (F1, F2 and F3) were found to have similar pH values (3.35 - 3.79) which is acidic (Table 3). These preparations have the tendency to cause irritation of the skin upon long usage since $\mathrm{pH}$ is incompatible with that of the skin.

Table 3. $\mathrm{pH}$ of the formulated Acacia nilotica seed extract (ANSE) creams and ointments.

\begin{tabular}{cc}
\hline Batch & $\mathbf{p H}$ \\
\hline F0 & $6.17 \pm 0.06$ \\
FP & $6.32 \pm 0.05$ \\
F1 & $3.35 \pm 0.02$ \\
F2 & $3.79 \pm 0.03$ \\
F3 & $3.50 \pm 0.05$ \\
S0 & $4.25 \pm 0.46$ \\
S1 & $5.20 \pm 0.56$ \\
S2 & $5.49 \pm 1.34$ \\
S3 & $7.69 \pm 2.10$ \\
\hline
\end{tabular}

Therefore, it will be necessary to incorporate a buffer agent to increase the $\mathrm{pH}$ to acceptable level (between 4 and 6); those of F0 and FP were considerably higher (6.17 and 6.32 respectively). These are blank bases without the extract, therefore alteration in the $\mathrm{pH}$ could be attributed to the presence of the extract in the formulations. The $\mathrm{pH}$ of the ointments, S1, S2 and S3 were between 5.20-7.69. The skin's protective acid mantle is a very fine, slightly acidic film on the surface of the skin acting as a barrier to microorganisms and other potential intruders that might penetrate the skin. An increase in the $\mathrm{pH}$ of stratum corneum can disrupt the enzymatic activities involved in keratinization, barrier restoration and antimicrobial function. Therapeutic agents and chemicals applied to the skin are essential exogenous factors that may stabilize the skin's acid mantle. Since the $\mathrm{pH}$ of a healthy human skin should be slightly acidic, lying between 4 and 6 , the use of topical preparations with near physiologic $\mathrm{pH}$ are believed to be the best in the prevention and treatment of skin abnormalities. 
The viscosity (Table 4) of the ointment formulations was high and increased with increase in concentration of the extract. It implies therefore that the extract had stiffer consistency thus making the viscosity much higher. There were also significant differences $(\mathrm{p}<0.05)$ in the viscosity of the formulations and the base. Generally, ointments are formulations with high viscosity which cling to the skin as films until a force is applied before it can flow. Among semi solid formulations, ointments are more viscous than creams due to the high water content in the latter, but are less viscous than pastes which usually have a high amount of powdered materials.

The effect of shear rate on the viscosity of the ointment formulations is presented in Figure 1. As shear rate increased, the viscosity of the formulations decreased. This is therefore a shear thinning behaviour which implies that when the ointment is applied to the skin by applying rubbing force, flow will be enhanced, depending on the rate of shear.

Table 4. Physicochemical properties of ointment formulations of Acacia nilotica seed extract.

\begin{tabular}{llllll}
\hline $\begin{array}{l}\text { Formulation } \\
\text { code }\end{array}$ & $\begin{array}{l}\text { Viscosity } \\
(\mathbf{c P})\end{array}$ & $\begin{array}{l}\text { Density } \\
(\mathrm{g} / \mathrm{mL})\end{array}$ & $\begin{array}{l}\text { Extrudability } \\
\mathbf{( g / s e c})\end{array}$ & $\begin{array}{l}\text { Spreadability } \\
\text { (g.cm/sec) }\end{array}$ & $\begin{array}{l}\text { Occlusion } \\
\text { factor }(\%)\end{array}$ \\
\hline S0 & $91.330 \pm$ & $0.804 \pm$ & $0.0413 \pm$ & $0.173 \pm$ & 75 \\
& 6.43 & 0.012 & 0.0004 & 0.005 & \\
S1 & $298.667 \pm$ & $0.996 \pm$ & $0.0450 \pm$ & $0.196 \pm$ & 25 \\
& 39.46 & 0.003 & 0.0014 & 0.004 & \\
S2 & $378.000 \pm$ & $1.016 \pm$ & $0.0475 \pm$ & $0.115 \pm$ & 50 \\
& 18.33 & 0.011 & 0.0007 & 0.001 & \\
S3 & $864.667 \pm$ & $1.028 \pm$ & $0.0535 \pm$ & $0.095 \pm$ & 75 \\
& 8.33 & 0.013 & 0.0021 & 0.002 & \\
\hline
\end{tabular}

S0 = formulation containing Shea butter alone.

S1, S2 and S3 = formulations containig ANSE at concentrations of 5.0, 7.5 and $10.0 \% \mathrm{w} / \mathrm{w}$ respectively.

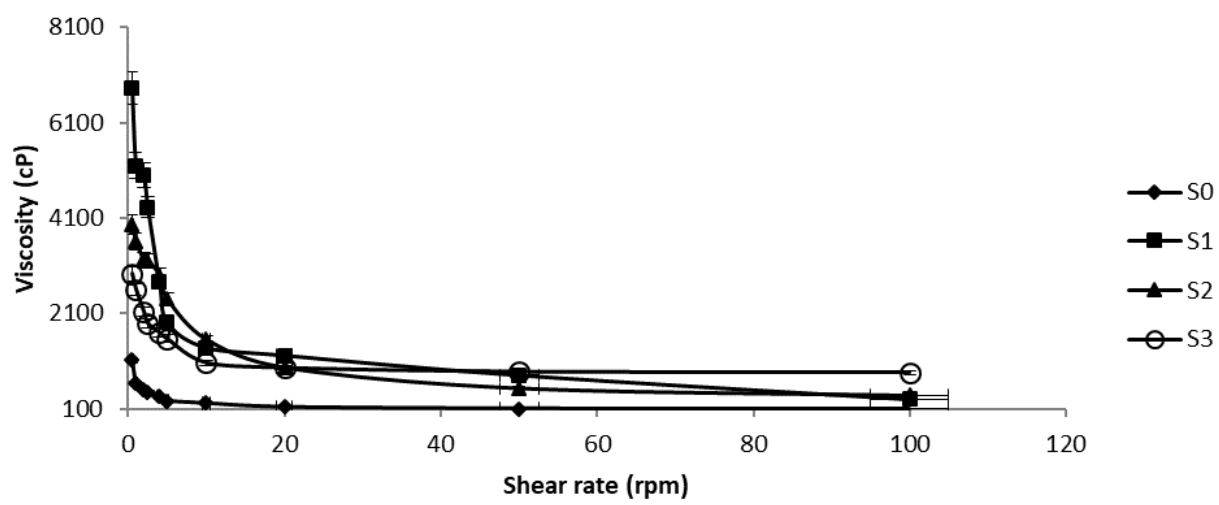

Figure 1. The effect of shear rate on the viscosity of the ointment formulations.

In addition, Figure 2 shows the rheological pattern of the ointment formulations with a plot of shear stress against shear rate and it depicts pseudoplastic rheological flow. Ointments generally cling as films until stress is applied before it begins to flow. In terms of viscosity, the ointment formulations are acceptable.

The density (Table 4 ) of the ointment ranged from $0.804 \pm 0.012$ to $1.028 \pm 0.013 \mathrm{~g} / \mathrm{mL}$. The denser the formulation, the more viscous they were, hence, density is directly related to the rheology of the ointments. The ranking of the density was $\mathrm{S} 0>\mathrm{S} 1>\mathrm{S} 2>\mathrm{S} 3$. S3 had the highest density and it was the most viscous of all the ointment formulations while $\mathrm{S} 0$ had the least density and expectedly it was the least viscous.

Extrudability (Table 4) refers to the ease of removal of a semi-solid formulation like creams, ointments and gels from tubes or any material with an orifice. The extrudability of the ointment formulations ranged from $0.041-0.052 \mathrm{~g} / \mathrm{sec}$. This property can make the creams to be easily ejected from tubes and make it easier for the user. A patient that needs to apply a pharmaceutical ointment should find it user-friendly, meaning the formulation should come out easily from the tube and applied locally on the affected part of the skin. It is also important that the formulations should not run out too fast otherwise wastage will occur thus depriving the patient optimal pharmaco-economic benefit from the product. In terms of extrudability, the formulations were acceptable. 


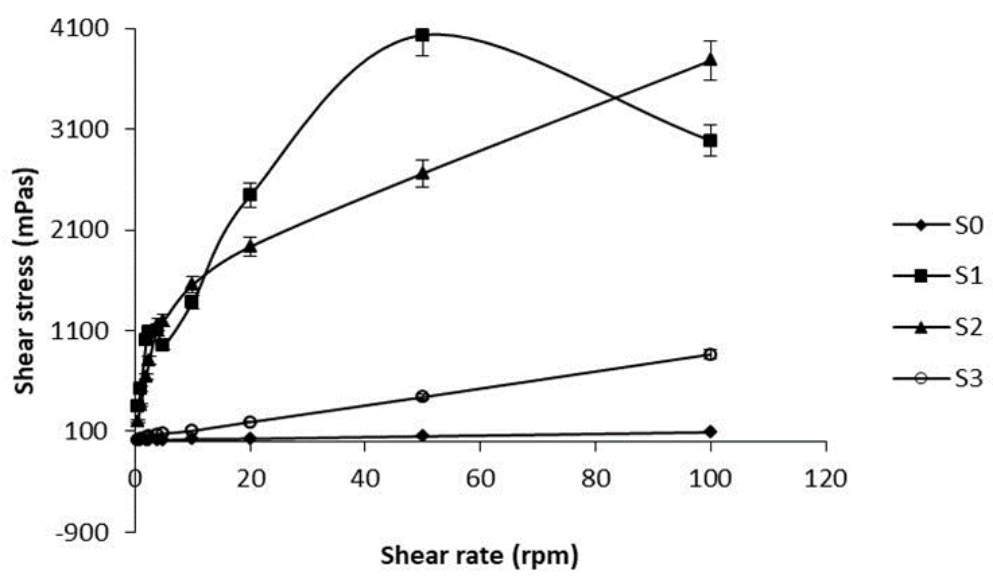

Figure 2. Shear stress versus shear rate plots for the ointment formulations.

The efficiency of topical and dermatological therapy depends on the way in which the patient spreads the formulation in even layers to administer a standard amount [38]. Spreadability denotes the extent of area to which the formulation spreads on application to the skin or affected part. Spreadability is therefore an important characteristic of these formulations and it is responsible for correct dosage delivery to the target site. Semi solid formulations should spread easily without much drag and this is usually affected by the type of base present. It should not produce friction in the rubbing process [38].

The analysis of spreadability has also been used to assess the quantitative and qualitative bioequivalence of semi-solid pharmaceutical formulations [39]. The ointment formulations spread within seconds and spreadability ranged between $0.095 \pm 0.002$ to $0.196 \pm 0.004 \mathrm{~g} . \mathrm{cm} / \mathrm{sec}$. This indicates that it will be easy and faster for the active constituents to be released for activity on the skin. Generally, the formulated creams in this study presented acceptable spreadability without any undue friction.

Skin occlusion by topical preparations offer diverse changes in hydration status, microbial presence, barrier permeability and lipids present in the epidermis, and may improve percutaneous absorption of chemical agents [40]. In addition, the rate of occlusion of topical formulations generally occur in the following order: occlusive film $=$ transdermal patches $>$ lipophilic ointments $>\mathrm{w} / \mathrm{o}$ cream $>$ oil/water cream. Occlusive vehicles are likely to increase the skin temperature by $2-3^{\circ} \mathrm{C}$ resulting in increased intermolecular motion and permeability. It is therefore imperative to determine this parameter in new formulations.

The results of the occlusion factor (Table 4) for the ointment formulations was in the ranking order of $\mathrm{S} 0=\mathrm{S} 1>\mathrm{S} 2>\mathrm{S} 3$. The occlusion for S3 and the base, $\mathrm{S} 0$ could be described as moderately high. However as the extract concentration reduced, a downward shift in the occlusion properties was observed. The occlusion property of the ointment formulations is generally influenced by the lipophilicity of the extract incorporated. Methanol was used to extract Acacia nilotica seed and generally, unlike non-polar solvents, methanol will obtain both polar and non-polar phytoconstituents from the seed. This implies that the lipophilicity of the extract could be regarded as multidimensional.

Ointment formulation (S3) of all the preparations demonstrated inhibitory activity against the six pathogenic organisms commonly responsible for human infections. This formulation also exhibited an impressive Minimum Inhibitory Concentration (MIC) of $0.5 \mathrm{mg} / \mathrm{ml}$, wider zones of inhibition, with the highest value being $20.0 \pm 0.5 \mathrm{~mm}$ and broad spectrum of activity as it inhibited both Gram positive and negative organisms (Table 5). This result is consistent with previous reports from our laboratory [27]; we had reported earlier that, in vitro time-kill kinetics antibacterial study of Acacia nilotica was assessed against Pseudomonas aeruginosa, Escherichia coli and Staphylococcus aureus determined by plate count technique and analyzed by percentage and log reduction. All test organisms were susceptible to the aqueous methanol extract. The minimum inhibitory concentration ranged between 0.5 and $1 \mathrm{mg}$, while minimum bactericidal concentration ranged between $\geq 1$ and $\geq 2 \mathrm{mg} / \mathrm{ml}$. The next active sample was reference formulation (Neomycin cream) that inhibited 3 Gram negative organisms (E.coli, K. pneumonia and P. aeruginosa) but the activity was not as high as that of test formulation S3 (Table 5), it is exciting that antibacterial activity of S3 compares favorably with that of ciprofloxacin and this observation corroborates natural product researchers opinion that, resistance to multicomponent preparations, as is seen in herbal medicines, develops less rapidly [9]. The formulated creams and ointments were also tested against clinical isolate of Salmonella typhi, and it 
was only susceptible to S3 confirming the potent range effect of S3. The inhibition of the growth of the organisms observed in our study is probably as a result of disruption in the architecture of the microorganism's cell wall, leading to changes in membrane penetrability, and consequent cell destruction [41, 42].

Table 5. Inhibition zones ( $\mathrm{mm}$ ) of the formulated creams and ointments on selected microorganisms.

\begin{tabular}{|c|c|c|c|c|c|c|}
\hline $\begin{array}{l}\text { Samples/ } \\
\text { Concentration } \\
(\mathrm{mg} / \mathrm{mL})\end{array}$ & E. coli & $\begin{array}{l}\text { K. } \\
\text { pneumonia }\end{array}$ & S. aureus & $\begin{array}{l}\text { St. } \\
\text { pyrogens }\end{array}$ & $\begin{array}{l}P . \\
\text { aeruginosa }\end{array}$ & S. typhi \\
\hline F0 $(2 \mathrm{mg} / \mathrm{mL})$ & NA & NA & NA & NA & NA & NT \\
\hline$(1 \mathrm{mg} / \mathrm{mL})$ & NA & NA & NA & NA & NA & NT \\
\hline $\mathrm{FP}(2 \mathrm{mg} / \mathrm{mL})$ & NA & NA & NA & NA & NA & NA \\
\hline$(1 \mathrm{mg} / \mathrm{mL})$ & NA & NA & NA & NA & NA & NA \\
\hline $\mathrm{F} 1(2 \mathrm{mg} / \mathrm{mL})$ & NA & NA & NA & NA & NA & NA \\
\hline (1 mg/mL) & NA & NA & NA & NA & NA & NA \\
\hline $\mathrm{F} 2(2 \mathrm{mg} / \mathrm{mL})$ & NA & NA & NA & NA & NA & NA \\
\hline$(1 \mathrm{mg} / \mathrm{mL})$ & NA & NA & NA & NA & NA & NA \\
\hline F3 $(2 \mathrm{mg} / \mathrm{mL})$ & NA & NA & NA & NA & NA & NT \\
\hline (1 mg/mL) & NA & NA & NA & NA & NA & NT \\
\hline $\mathrm{SO}(2 \mathrm{mg} / \mathrm{mL})$ & NA & NA & NA & NA & NA & NT \\
\hline (1 mg/mL) & NA & NA & NA & NA & NA & NT \\
\hline $\mathrm{S} 1(2 \mathrm{mg} / \mathrm{mL})$ & NA & NA & NA & NA & NA & NT \\
\hline (1 mg/mL) & NA & NA & NA & NA & NA & NT \\
\hline $\mathrm{S} 2(2 \mathrm{mg} / \mathrm{mL})$ & NA & NA & NA & NA & NA & NA \\
\hline (1 mg/mL) & NA & NA & NA & NA & NA & NA \\
\hline $\mathrm{S} 3(2 \mathrm{mg} / \mathrm{mL})$ & $19.0 \pm 0.3$ & $19.0 \pm 0.3$ & $20.0 \pm 0.5$ & $18.5 \pm 0.4$ & $19.5 \pm 0.5$ & $19.0 \pm 0.3$ \\
\hline$(1 \mathrm{mg} / \mathrm{mL})$ & $18.6 \pm 0.4$ & $18.5 \pm 0.4$ & $17.0 \pm 0.3$ & $17.5 \pm 0.3$ & $17.0 \pm 0.3$ & $8.5 \pm 0.4$ \\
\hline$(0.5 \mathrm{mg} / \mathrm{mL})$ & $16.5 \pm 0.4$ & $17.0 \pm 0.5$ & $8.5 \pm 0.3$ & $16.0 \pm 0.4$ & $16.5 \pm 0.3$ & NA \\
\hline $\begin{array}{l}\text { Ciprofloxacin } \\
\quad(10 \mathrm{mg} / \mathrm{mL})\end{array}$ & $30.0 \pm 0.4$ & $30.0 \pm 0.3$ & $30.0 \pm 0.3$ & $30.0 \pm 0.5$ & $30.0 \pm 0.3$ & $30.0 \pm 0.3$ \\
\hline $\begin{array}{l}\text { Neomycin cream } \\
\quad(2 \mathrm{mg} / \mathrm{mL})\end{array}$ & $11.0 \pm 0.3$ & $9.0 \pm 0.4$ & NA & NA & 10.0 & NT \\
\hline$(1 \mathrm{mg} / \mathrm{mL})$ & $10 \pm 0.4$ & $9.0 \pm 0.3$ & NA & NA & 8.0 & NT \\
\hline
\end{tabular}

NA $=$ No activity

NAT $=$ Not tested

$\mathrm{F} 0$ = formulation containing aqueous cream alone without preservative.

$\mathrm{FP}=$ formulation containing aqueous cream with preservative.

$\mathrm{F} 1, \mathrm{~F} 2$ and F3 = formulations containing ANSE at concentrations of 5.0, 7.5 and $10 \% \mathrm{w} / \mathrm{w}$ respectively.

$\mathrm{S} 0$ = formulation containing She butter alone.

S1, S2 and S3 = formulations containing ANSE at concentrations of 5.0, 7.5 and $10 \% \mathrm{w} / \mathrm{w}$ respectively.

It could also be attributed to penetration of phytochemicals into bacteria cells thus stimulating coagulation of cell contents. Tannins which are present in ANSE have been confirmed to have antimicrobial effect.

\section{CONCLUSION}

The ointment formulation at $10 \% \mathrm{w} / \mathrm{w}$ concentration showed potentials for use in the treatment of wound and skin infections. It could therefore be developed for commercial use.

\section{MATERIALS AND METHODS}

\subsection{Materials}

Fruit pods of Acacia nilotica plant, liquid paraffin, emulsifying wax (Fisher Chemicals, USA), methanol (Loba Chemie, India) white soft paraffin (Fisher Chemicals, USA), Shea butter purchased from a metropolitan market in Abuja, all other chemicals used were of Analar grade. 


\subsection{Method}

\subsubsection{Collection of materials}

The fruit pods of Acacia nilotica were obtained from the botanical garden of the National Institute for Pharmaceutical Research and Development (NIPRD), Abuja, Nigeria and was identified, assigned voucher no NIPRD/H/7008 and kept in the Institute's herbarium. The dried seeds were removed from the pods, pulverized and sieved using the $600 \mu \mathrm{m}$ mesh size to obtain uniform particle sizes. The sieved material was packaged in an air-tight container and stored until further use.

\subsubsection{Preparation of dried seed extracts}

The dried pulverized and sieved Acacia nilotica seeds (293 g) was macerated in absolute methanol (1:8) at room temperature for $48 \mathrm{~h}$. The supernatant was decanted and concentrated over a water bath (Karl Kobb, Derieich West Germany) at $40^{\circ} \mathrm{C}$. The weight of the resulting dried product (ANSE) was determined, the product was packaged in an air-tight container and kept in a desiccator.

\subsubsection{Preparation of cream formulations}

Emulsifying ointment (100 g) was prepared using the official formula [43]; white soft paraffin and emulsifying wax were weighed into a beaker and allowed to melt over a water bath at $70^{\circ} \mathrm{C}$ then liquid paraffin was incorporated and the mixture stirred together. This was used as the vehicle for the formulation of the creams. The creams containing the extract (ANSE) were then prepared using the composition of ingredients stated in Table 1. Appropriate quantities of the prepared emulsifying ointment was heated in a beaker over the water bath at $70^{\circ} \mathrm{C}$, this served as the oily phase. The aqueous phase on the other hand was prepared by weighing the required quantity of water into another beaker and heating to $75^{\circ} \mathrm{C}$ on the water bath. The preservatives (methyl paraben and propyl paraben) were also placed into the water. The oily portion was then added to the aqueous phase while stirring until completely homogenized and cooled. This water miscible base was blended together, in aliquots, with the required quantity of ANSE already in the mortar using a pestle, tween 20 was also incorporated (where necessary). The contents of the mortar were triturated together until a creamy product was obtained. The creams so prepared were packaged in appropriate containers and kept for further analysis.

\subsubsection{Preparation of ointment formulations}

Shea butter was used as the ointment base. Formulations containing the base and Acacia nilotica seed extract (ANSE) were prepared using the compositions in Table 1. Appropriate quantities of Shea butter was weighed and melted in a beaker over the water bath. The melted base was integrated in aliquots into the appropriate amount of ANSE already in the mortar using a pestle until a completely homogenous mixture was obtained. The prepared ointment was then poured into ointment jars and stored for further analysis.

\subsection{Evaluation of formulated ANSE creams and ointments}

\subsubsection{Physical evaluation}

The appearance, color, odor, texture, homogeneity, ease of application and removal, irritancy test and phase separation of the different formulated creams and ointments were evaluated.

\subsubsection{Chemical evaluation}

\section{Determination of $\mathrm{pH}$}

The $\mathrm{pH}$ of the formulated undiluted creams and ointments were measured using the digital $\mathrm{pH}$ meter (Denver $\mathrm{pH}$ meter). Values for three determinations were obtained and the average calculated.

\section{Evaluation of extract-base compatibility}

The occurrence of any physical incompatibility between the extract and base in the formulated creams and ointments was visually assessed and recorded.

\section{Evaluation of formulation stability}

The prepared creams and ointments were stored at room temperature for 90 days and visually assessed for presence/absence of growth. 


\section{Determination of viscosity of ointment formulations}

The Brookfield viscometer (VT 181, Karlsruhe, Germany) was used to determine the viscosity of the ointment formulations at $29.40 \pm 2.50 \mathrm{C}$. Spindle 7 was used and ten different shear rates ( 0.5 to $100 \mathrm{rpm})$ were applied. The shear stress was determined by calculation and appropriate plots provided.

\section{Determination of ointment density}

Syringe $(2 \mathrm{~mL})$ was weighed on the balance, filled with ointment sample and re-weighed. The weight of the cream was determined by subtracting the weight of the filled syringe from that of the unfilled syringe and the density was calculated in $\mathrm{g} / \mathrm{mL}$. The procedure was repeated for other ointment samples.

\section{Determination of ointment extrudability}

An empty syringe $(2 \mathrm{~mL})$ was weighed, and the syringe was filled with the ointment sample and then reweighed. The rate of extrusion was standardized (1press/sec) and the ointment was released. The time it takes the cream to be extruded from the syringe completely was recorded using stop watch. The procedure was repeated for other cream samples. Extrudability was then calculated in $\mathrm{g} / \mathrm{sec}$. The procedure was repeated for other ointment samples.

\section{Determination of ointment spreadability}

Ointment was weighed $(500 \mathrm{mg})$ unto a slide and another slide used to cover it. A weight of $200 \mathrm{~g}$ was placed on top of the cover slide and the ointment was allowed to spread maximally for five minutes. Without removing the cover slide, the extent of ointment spread was measured in four different directions and the average obtained in $\mathrm{cm}$. The time used to separate the upper slide from the lower was also obtained using a stop watch. Spreadability was calculated in $\mathrm{g} . \mathrm{cm} / \mathrm{sec}$. The procedure was repeated for the remaining ointment samples.

\section{Determination of occlusion properties}

Each ointment formulation was carefully weighed $(200 \mathrm{mg})$ on a filter paper and evenly spread out. This was then placed on a clean sample bottle having 2.3 diameter surface. The average perimeter of the filter paper was $22.9 \mathrm{~cm}$. Distilled water $(20 \mathrm{~mL})$ was carefully transferred into each bottle and the filter paper containing the spread cream was placed on top to cover the entire orifice of the bottle. The water loss was determined at 24-144 h; controls with ordinary filter paper i.e. positive control (CP) and without any filter paper i.e. negative control $(\mathrm{CN})$ were set up as well. Readings were taken every $24 \mathrm{~h}$. The occlusion factor $(\mathrm{F})$ was calculated using the equation below:

$$
\mathrm{F}=(\mathrm{A}-\mathrm{B} / \mathrm{A}) \times 100
$$

where, B is the water loss from the test formulations; A is the water loss of the filter without a sample (blank reference). An occlusion factor of zero indicated no occlusive effect compared with the reference, and 100 was the maximum occlusion factor [44].

\subsubsection{Microbiological assay of prepared ANSE creams and ointments}

Overnight broth cultures of the test organisms viz; Staphylococcus aureus ATCC, Pseudomonas aeruginosa ATCC, Escherichia coli ATCC and clinical isolates of Klebsiella pneumonia, Streptococcus pyrogens and Salmonella typhi from Diagnostic Laboratory of National Institute for Pharmaceutical Research and Development were diluted to $107 \mathrm{cfu} / \mathrm{mL}$ using a UV-vis spectrophotometer [45] and plated on Nutrient agar. Two to three colonies of $20 \mathrm{~h}$ growth on Mueller Hinton agar of the organisms to be studied were suspended in $50 \mathrm{~mL}$ prewarmed $\left(37^{\circ} \mathrm{C}\right)$ Mueller Hinton broth. This was incubated overnight at $37^{\circ} \mathrm{C}$ diluted $1 / 2500$ using the medium and maintained in water bath while being agitated $(50 \mathrm{rpm})$. The optical density of the culture was observed at $450 \mathrm{~nm}$ until an absorbance of 0.1 equivalent 2.5-3.0 $107 \mathrm{cfu} / \mathrm{mL}$ for E.coli and P.aeruginosa and 1.8-2.0 $\mathrm{x}$ 107 for S. aureus was reached. Molten Mueller Hinton agar $(25 \mathrm{~mL})$ maintained in a water bath at $50^{\circ} \mathrm{C}$ was inoculated with $100 \mu \mathrm{L}$ standardized organism, allowed to gel in sterile Petri dish. Equidistant grooves of 5 $\mathrm{mm}$ diameter was bored, sealed with a drop of agar and filled with $200 \mu \mathrm{L}(2,1 \mathrm{mg}$ respectively) of cream solution prepared by dissolving $1 \mathrm{~g}$ in $10 \mathrm{~mL}$ of $50 \%$ aqueous tween 80 , further diluted by $1: 10$ in sterile broth as experimental solution. The plates were allowed to stand for $2 \mathrm{~h}$ and incubated at $37^{\circ} \mathrm{C}$ for $18-24 \mathrm{~h}$. Post incubation, the zones of inhibition were determined by measuring the zones where there was no growth. 
This process was performed twice to obtain data in duplicates. Control plate of ciprofloxacin $10 \mu \mathrm{g} / \mathrm{ml}$ (HIMEDIA Laboratories Pvt. Ltd, India).

Acknowledgements: The authors are grateful to the technical staff of the Department of Pharmaceutical Technology and Raw Materials Development, National Institute for Pharmaceutical Research and Development (NIPRD) for their assistance during the period this study was conducted and also Mallam Muazam of the Department of Medicinal Plant Research and Traditional Medicine for his help in the identification of the plant material.

Author contributions: Concept - O.A., O.O.; Design - O.A., O.O.; Supervision - O.O., O.A.; Resources - Y.I., O.A.; Materials - Y.I., T.A.; Data Collection and/or Processing - O.O., K.E., Y.I., J.J., M.E., P.O.; Analysis and/or Interpretation - M.E., T.A., K.E., J.J.; Literature Search - O.O., T.A.; Writing - T.A., P.O.; Critical Reviews - Y.I., O.A., T.A., O.O., P.O., J.J., K.E., M.E.

Conflict of interest statement: The authors declare no conflict of interest.

\section{REFERENCES}

[1] Banso A. Phytochemical and antibacterial investigation of bark extracts of Acacia nilotica. J Med Plants Res. 2009; 3(2): 82-85.

[2] Dabur R, Amita G, Mandal T, Desh D, Vivek B, Gurav A, Lavekar G. Antimicrobial activity of some Indian medicinal plants. Afr J Tradit Complement Altern Med. 2007; 3: 313-318.

[3] Costelloe C, Metcalfe C, Lovering A, Mant D, Hay A. Effect of antibiotic prescribing in primary care on antimicrobial resistance in individual patients: systematic review and meta-analysis. Br Med J. 2010; 340: 2096. [CrossRef]

[4] Cope A, Chestnutt IG. Inappropriate prescribing of antibiotics in primary dental care: Reasons and resolutions. Prim Dent J. 2014; 3: 33-37. [CrossRef]

[5] Hassali MA, Kamil TK, Md Yusof FA, Alrasheedy AA, Yusoff ZM, Saleem F, Al-Tamimi SK, Wong ZY, Aljadhey H, Godman B. General practitioners; knowledge, attitude and prescribing of antibiotics for upper respiratory tract infections in Selangor, Malaysia: findings and implications. Expert Rev Anti Infect Ther. 2015; 13(4): 511-520. [CrossRef]

[6] Brink AJ, Van Wyk J, Moodley VM, Corcoran C, Ekermans P, Nutt L, Boyles T, Perovic O, Feldman C, Richards G, Mendelson $\mathrm{M}$. The role of appropriate diagnostic testing in acute respiratory tract infections: An antibiotic stewardship strategy to minimise diagnostic uncertainty in primary care. S Afr Med J. 2016; 106: 554-561. [CrossRef]

[7] Sandoval-Motta S, Aldana M. Adaptive resistance to antibiotics in bacteria: a systems biology perspective. Wiley Interdiscip Rev Syst Biol Med. 2016; 8: 253-267. [CrossRef]

[8] Ogochukwu U, Christianah I, Marlene E, Sabinus O, Martins E. Quality assessment of some brands of clarithromycin and azithromycin tablets using the concept of dissolution efficiency and similarity factor. Int J Pharm Sci Res. 2018; 9(12): 5401-5410. [CrossRef]

[9] Emeje MO, Izuka A, Isimi CY, Ofoefule SI, Kunle OO. Preparation and Standardization of a herbal agent for the therapeutic management of Asthma. Pharm Dev Technol. 2011; 16(2): 170-178. [CrossRef]

[10] Bennison JJ, Paterson RT, The use of Trees by Livestock, Acacia production programme, Chatham, UK 1994.

[11] Okoro SO, Kawo AH, Arzai AH. Phytochemical screening, antibacterial and toxicological activities of Acacia nilotica extracts. Bayero J Pure Appl Sci Technol. 2014; 7(1): 105-115. [CrossRef]

[12] Meena PD, Kaushik P, Shukla S, Soni AK, Kumar M, and Kumar A. Anticancer and antimutagenic properties of Acacia nilotica (Linn.) on 7, 12-dimethylbenz (a) anthracene-induced skin papillomagenesis in Swiss albinomice. Asian Pac J Cancer Prev. 2006; 7: 627-632.

[13] Singh BN, Singh BR, Singh RL, Prakash D, Sarma BK, Singh HB. Antioxidant and anti-quorum sensingactivities of green pod of Acacia nilotica L. Food Chem Toxicol. 2009; 47: 778-786. [CrossRef]

[14] Sultana B, Anwar F, Przybylski R. Antioxidant activity of phenolic components present in barks ofAzadirachta indica, Terminalia arjuna, Acacia nilotica, and Eugenia jambolana Lam. trees. Food Chemistry. 2007; 104: 1106-1114. [CrossRef]

[15] Fagg C. Acacia nilotica: pioneer for dry lands. In: Roshetko JM. (Ed). Agroforestry species and technologies. Winrock International, Arizona, pp. 23-24

[16] Spies P, March N. Prickly acacia-approaches to the management of prickly acacia (Acacia nilotica) in Australia. Department of Natural Resources, Mines and Energy, Queensland, Australia, 2004. 
[17] Aliyu BS, Common ethnomedicinal plants of the semiarid regions of West Africa, Triumph, Nigeria 2006.

[18] El-Kamali HH, El-Karim EMA. Evaluation of antibacterial activity of some medicinal plants used in Sudanese traditional medicine for treatment of wound infections. Acad J Plant Sci. 2009; 2(4): 246-251.

[19] Kossi M, Tchin D, Povi LE, Kwashi EG, Kodjo AA, Gado N, Messanvi G. Effect of topical application of hydroethanolic extract of Acacia nilotica pods on second-degree cutaneous infected burns. Eur Sci J. 2012; 10(30): 24-29.

[20] Gilani AH, Shaheen F, Zaman M, Janbaz KH, Shah BH, Akhtar MS. Studies on antihypertensive and antispasmodic activities of methanol extract of Acacia nilotica pods. Phytother Res. 1999; 13: 665- 669. [CrossRef]

[21] Kalaivani T, Mathew L. Free radical scavenging activity from leaves of Acacia nilotica (L.) Wild. ex Delile, an Indian medicinal tree. Food Chem Toxicol. 2010; 48: 298-305. [CrossRef]

[22] Badshah L, Hussain F. People preferences and use of local medicinal flora in District Tank, Pakistan. J Med Plants Res. 2011; 5(1): 22-29.

[23] El-Tahir A, Satti GM, Khalid SA. Antiplasmodial activity of selected sudanese medicinal plants with emphasis on Acacia nilotica. Phytother Res. 1999; 13: 474-478.

[24] Alli LA, Adesokan AA, Salawu OA, Akanji MA, Tijani AY. Anti-plasmodial activity of aqueous root extract of Acacia nilotica. Afr J Biochem Res. 2011; 5(7): 214-219.

[25] Jigam AA, Akanya HO, Dauda BEN, Okogun JO. Polygalloyltannin isolated from the roots of Acacia nilotica Del. (Leguminoseae) is effective against Plasmodium berghei in mice. J Med Plants Res. 2010; 4(12): 1169-1175.

[26] Sanni S, Thilza IB, Mohammed SA, Sanni FS, Okpoli LA, Jajere MS, Talle M. The effect of Acacia nilotica pod Ethyl Acetate fraction on induced diarrhea in albino rats. N Y Sci J. 2010; 3(8): 16-20.

[27] Oladosu PO, Isu NR, Ibrahim K, Orishadipe AT, Lawson L. Antituberculosis activity of bioactive compounds from fruit extract of Acacia nilotica. J Microbiol Res. 2013; 3(6): 247-254.

[28] Abeer MHA, Sanaa OY. Anti-microbial activity of Acacia nilotica extracts against some bacteria isolated from clinical specimens. Res J Med Plant. 2007; 1(1): 25-28. [CrossRef]

[29] Kossi M, Darré T, Daubeuf F, Lawson-Evi P, Eklu-Gadegbeku K, Aklikokou K, Napo-Koura G, Frossard N, Gbeassor M. Effect of topical application of hydro-ethanolic extract of acacia nilotica pods on second-degree cutaneous infected burns. J Pharm Nutr Sci. 2015; 5: 24-29. [CrossRef]

[30] Manga SS, Isah M, Danlami MB. Comparative antibacterial activity of Acacia nilotica wild. leaf extracts against multi drug resistant bacteria. UJMR J Microbiol Res. 2018; 3(1): 98- 103.

[31] Idson B, Lazarus J. Semisolids in the Theory and Practice of Industrial Pharmacy. In: Lachman L, Lieberman HA, Kanig JL. (Eds). Varghese Publishing House, Bombay, India, 1991, pp.534-563.

[32] Lachman L, Lieberman HA, Kanig JL. Theory \& Practice of industrial pharmacy, second ed., Lea \& Fepharbieger, Philadelphia, USA 1976.

[33] Gupta P, Garg S. Recent Advances in semisolid dosage forms for dermatological application. Pharm Tech. 2002; 1: 144-162.

[34] New TR. Biology of Acacias, Oxford University Press, Melbourne 1984.

[35] Lutterodt GD, Ismail A, Basheer, RH, Baharudin HM. Antimicrobial effects of Psidium guajava extracts as one mechanism of its antidiarrheal action. Malays J Med Sci. 1999; 6(2): 17- 20.

[36] Cowan MM. Plant products as antimicrobial agents. Clin Microbiol Rev. 1999; 12(4): 564-582.

[37] Aremu OI, Badru OH, Oyemade, OA. Comparative effectiveness of certain antimicrobial agents in semi-solid preparations. Afr Res Rev. 2009; 3(4): 244-247.

[38] Nayeem N, Karvekar MD. Stability studies abd evaluation of the semi-solid dosage form of the rutin, qurcitin, ellagic acid, gallic acid and sitosterol isolated from the leaves of Tectona grandis for wound healing activity. Arch Appl Sci Res. 2011; 3(1): 43-51.

[39] Tian F, Li B, Ji B, Zhang G, Luo Y. Identification and structure-activity relationship of gallotannins separated from Galla chinensis. LWT-Food Sci Technol. 2009; 42: 1289-1295. [CrossRef]

[40] Zhai H, Maibach HI. Effects of skin occlusion on percutaneous absorption: an overview. Skin Pharmacol Appl Skin Physiol. 2001; 14(1): 1-10. [CrossRef]

[41] Taguri T, Tanaka T, Kouno I. Antibacterial spectrum of plant polyphenols and extracts depending upon hydroxyphenyl structure. Biol Pharm Bull. 2006; 29(11): 2226-2235. [CrossRef] 
[42] Kryscio DR, Sathe PM, Lionberger R, Yu L, Bell MA, Jay M, Hilt JZ. Spreadability Measurements to Assess Structural Equivalence (Q3) of Topical Formulations - A Technical Note. AAPS PharmSciTech. 2008; 9(1): 84. [CrossRef]

[43] British Pharmacopoeia. British Pharmacopoeia Office: MHRA, 151 Buckingham Palace road, London SW1W9SZ 2013.

[44] Wissing S, Lippacher A, Müller R. Investigations on the occlusive properties of solid lipid nanoparticles (SLN). J Cosmet Sci. 2001; 52: 313-324.

[45] Dominiguez MC, Manuel R, Victoria MB. Application of spectrophotometric method for the determination of postantibiotic effect and comparism with viable counts in agar. J Antimicrob Chemother. 2001; 47: 391-398. [CrossRef]

This is an open access article which is publicly available on our journal's website under Institutional Repository at http://dspace.marmara.edu.tr. 